\title{
Training Law Academicians in the Art of Teaching and Learning: A Value Added Approach to Pedagogy
}

\author{
Kola O. Odeku \\ Faculty of Management and Law, School of Law, \\ University of Limpopo, South Africa \\ E-mail:kooacademics@gmail.com
}

Doi:10.5901/mjss.2013.v4n14p805

\begin{abstract}
This paper seeks to examine the recent initiative commenced by the Dean of Faculty of Management and law, University of Limpopo, Turfloop, South Africa to ensure that all academic staff members in the Faculty undergo training on teaching and learning in the higher education in order to improve the quality and standard of pedagogy. This is against the backdrop that Lecturers are usually appointed to provide teaching and learning to the students based on discipline related or specific areas without having formal training in the art of teaching and learning. In view of the fact that there have been persistent complaints of lower standard in education attributable to poor performances at the workplaces, the Department of Higher Education in South Africa has put in place, policy to ensure that academicians are trained to enhance the quality of teaching and learning. The paper highlights the importance of the training and concludes that it was a step taken in the right direction. In conclusion, the paper presents the prospects and impact of the training and recommends that it should be made compulsory.
\end{abstract}

Keywords: Improved Quality of Pedagogy, Law lecturers, mind-sets, Alignments, value-added.

\section{Introduction}

Delivering pedagogy efficiently and effectively at a university is a very complex issue (Garrison and Kanuka 2004). Lecturers from different disciplines within the university setting have their own perspectives on how best to deliver teaching and learning (Barr and Tagg 1995). In most cases, lecturers believe that the methods they use are the best (Healey, 2000). With regard to law lecturers, most of them were well trained in the arts of law at the university in order to become advocates and attorneys, legal consultants and some may dabble into academics. However, with regard to the issue of becoming academic law lecturers, few have received formal training on how to teach law at the university or have acquired understanding of how learning occurs during the course of teaching (Trail et al., 1996). It is, therefore, important to point out that, irrespective of what the law degree received would be used for, all law students received the same education and training at the university and it is after graduation that they might consider delving into fields or careers of their choices (Thomas et al., 1990). This is the reason why those of them who decided to join the academic staff in the university are considered not to have received any formal education or training in the art of teaching and learning but have only received a discipline-based education to become lawyers: advocates, attorneys, company secretary and legal consultants. For those who would want to become academics, one of the requirements is to possess the postgraduate Master of Laws degree. This is usually what is required for the entry point of becoming a law teacher in order to discharge the responsibility of law teaching and learning in Higher Education (Rosenthal 2011). Therefore, such would teach based on discipline-based approach and knowledge acquired during their studies at the university (Lueddeke 2003). As such, law lecturers use the method they perceived is the best way to teach provided it revolves about issues and principles of law without necessary concern as to whether learning has taken place (Ballantyne et al., 1999). To this end, teaching and learning is flexible and unregulated and there are usually inconsistencies in assessment criteria (D'Amato, 1987). Due to this poor teaching quality, law students become vulnerable because at the end of the day, they might not necessarily know what sort of assessment criteria will be used (Biggs and Tang, 2011). The consequence of this is that most of the students receive low and substandard education in law because of the poor strategy and modes of teaching and learning (Darling-Hammond 1999). Relying on educational scientific research studies which have been conducted by various experts in teaching and learning in South Africa and elsewhere, it was discovered that one of the reasons for poor performance of graduates produced by the universities at the workplaces was due mainly to poor, low quality and standard in the ways lecturers deliver teaching and learning to the students. 
Against the backdrop of this pitfall, the DoHE has started various reforms and transformations in pedagogy generally and particularly to train the lecturers in the art of improving and delivering quality and standard teaching and learning at the higher education in South Africa (Biggs and Tang 2011). Law as a discipline is no exception. Law lecturers are therefore also enjoined to align their teaching and learning to the new method prescribed by the DoHE (Sterling, 2012).

However, research has shown that this perception might be wrong because what is considered to be the best form of teaching and learning may not be good enough to achieve the desired learning outcomes (Biggs and Tang, 2011). Research has now confirmed that there should be coordinated and coherent approach to how lecturers deliver teaching and learning to students. Research has also confirmed that the business-as-usual in pedagogy is not sustainable because it is not producing the desired results (Fullan, 2007). Pursuant to this, Learners are known to be worse off, the failure rates have been increasing at an alarming and appalling rate, thus creating a likelihood of collapse of the tertiary educational system (Daniel, 2010). The concern is that those who made it and graduated were perceived by the society and the workplaces as not properly educated to take real life challenges because they were half-baked, with tendencies of not performing wherever they found themselves (Renton, 2009). Worse still, employers of skilled and managerial labour, especially products from universities, have continued to raise concern about the level of intelligence and the capacity of graduates produced to take up jobs in the workplaces (Livingstone, 2004). The backdrop of this is the socalled graduates who were not thoroughly taught by those who are given the responsibility to provide pedagogic services due mainly due to bad delivery of teaching and learning during the course of the studentship and learner ship of the graduates at the university (Moyles et al., 2011).

Pursuant to the above concerns, one of the ways out of the problem is to subject the lecturers themselves to training on how to provide high quality, viable and rewarding teaching and learning to the students (Von Glasersfeld, 1989). For long, this has been taken for granted by law lecturers and it has taken its toll on the teaching and learning of law (Von Glasersfeld 1989). It is pertinent to mention that, while the existing lecturers have to go through the training because they are already in the system, the would-be lecturers are expected to have been trained or trained. The Director of the School of Law took advantage of the call by the University and the Dean to train and expose lecturers to contemporary training in pedagogy by contacting the Tshwane University of Technology, Pretoria, South Africa - which is known for its expertise in conducting and providing courses on Higher Education Development and Support Curriculum Development and Support - to train academic law lecturers in the School of Law, Faculty of Management and Law, University of Limpopo, Turfloop Campus, South Africa. Three subject experts were detailed to facilitate the training at a designated venue. The Director circulated a related memo to all academics in the school, indicating that the training is compulsory and will run for a week. It is important to mention that, ordinarily, the training should have run for six months but this was not the case as it was compressed to run for a week. The implication of this is that trainees would have general knowledge on the art of teaching and learning in higher education but would not receive any credits or certificates of accomplishments in a formal academic sense. Therefore, the purpose was to introduce the course to the trainees by highlighting important aspects without subjecting them to the usual learning outcomes and assessments.

The objective of this paper is to examine and describe how the training on the new methods of pedagogy is expected to change teaching and learning techniques, perceptions and improve the quality and standard of the ways and manners law lecturers deliver pedagogy to the law students. During and at the end of the training, the trainees admitted that the new techniques and methods have given them a better picture on how to provide high-quality pedagogy to law students and with the belief that this will be maintained and become the generally acceptable standard. They also indicated that values have been added to them personally and this will definitely reflect on how they will henceforth disseminate quality and robust scholarship in teaching and learning to the law students. They also learnt that the training focused on how the lecturers have to improve their performances in the lecture halls, not only by achieving a better understanding of how lectures are delivered, but also on how learners learn. Another objective flowing from the key objective is to accentuate that there has therefore been tremendous improvements in the teaching and learning activities in the school and this is a testimony to the fact that the training received had a significant impact on the law pedagogic. Relying and using existing literature on how training could serve as an impetus to assist lecturers in enhancing and improving their teaching and learning skills, the paper vehemently argues that it is a right step in the right direction because of the academic value it has added culminating into robust and contemporary pedagogy by the trained lecturers.

\section{Literature Review}

The academic landscape is changing in the higher education because of the drive for excellence in teaching and learning, research and community development (Coaldrake and Stedman, 1999). As part of transformation, academics 
are now using different modern methods of teaching but this cannot replace the established method of 'contact teaching'. However, contact teaching itself is undergoing massive reform on a daily basis in order to make it more effective, efficient and of high quality. As Biggs (2001:221) observed that "assuring and enhancing the quality of teaching and learning in universities is currently of major concern." To this end, training becomes imperative for academics in order to keep abreast with the new skills and modes of maintaining and enhancing quality teaching and learning in the universities (Biggs, 2001). The training should also be of high quality. It should transform and add value to the academics in order for them to be able to deliver robust and high quality teaching and learning to the students. Emphasising on the overall benefit of high quality pedagogy, Biggs (2001:221) asserts that "quality teaching transforms students' perceptions of their world, and the way they go about applying their knowledge to real world problems; it also transforms teachers' conceptions of their role as teachers, and the culture of the institution itself." This is the vision of the Department of Higher Education in South Africa (DoHE). The DoHE has therefore mandates all universities in South Africa to start implementing various policies that have been put in place to transform and enhance the quality of teaching and learning in the universities.

These policies intervention reaffirm the willingness on the part of the policy makers and reformers in South Africa to challenge the unproductive and unsustainable ways and manners tertiary institutions and the lecturers deliver pedagogy to learners. The policy makers have therefore challenged those who are delivering pedagogic to ensure that there is consistency in the production of sustained improvement culminating in high quality of pedagogy in the tertiary institutions.

The policy relevant to this study is the recently gazetted Higher Education and Training (Notice 1040 of 2012; Government Gazette No. 36003 of 14 December 2012) in terms of the National Qualifications Act, 2008 (Act No. 67 of 2008) and as contemplated in the Higher Education Act, 1997 (Act No. 101 of 1997). To give effect to the provisions of this policy, experts in pedagogy have to be consulted to do the training. This was the reason why the Director of the School of Law, deriving inspiration from the academic leadership of the Dean of Faculty of Management and Law, contacted the service provider to conduct the training for academic staff members in the School of law.

\section{Teaching and Learning Activities during the Course of the Training}

There were three facilitators who taught the course based on the areas of their expertise. Training commenced by facilitators devoting an ample time to the general introduction and what the training set out to achieve. This is important because of the various backgrounds and already conceived mind-sets and business-as-usual discipline-based approach law lecturers were used to for delivering scholarship in teaching and learning of law. The facilitator informed the trainees that the course has been compressed in order for them to be able to teach for a week. They made the trainees understand that, ordinarily, the course should be taught for at least six months in order to earn credit and certification. Based on this background, the facilitators therefore focused on the key issues that would enable trainees to add value and improve on their teaching and learning skills. The facilitator read out the purpose of the course by saying: "is to enhance the quality of teaching and learning by emphasising issues that are integrally part of an academic's life. The course provides a general overview of teaching and learning with a focus on Higher Education and The Higher Education Qualifications Sub-Framework (HEQSF), Assessment and Teaching" (HEDSC, 2013). This assertion confirms that there is need for law lecturers to enhance the quality of teaching and learning based on the current requirements by the Department of Higher Education. This presupposes that the teaching and learning techniques being previously used in the School of Law need to change and conform to the new assessment requirement.

Against the backdrop of the reason for the new modes of delivering pedagogy, the facilitators highlighted that, at the end of the course, the learning outcomes will be that the law lecturers should be able to: "facilitate learning within an authentic environments, applying interactive teaching strategies; develop outcomes and assessment criteria following provided criteria, apply teaching and learning theories and principles by reflecting on current teaching and learning practices" (HEDSC, 2013).

In order to lay a solid foundation that led to proper comprehension of what would be taught, the facilitators provided general information on "the art of teaching and learning in Higher Education." To this end, the learning pyramid was used to explain the defects and shortcomings in how lecturers used to deliver teaching and learning in the classrooms. Thereafter, trainees were asked to evaluate and assess themselves using the pyramid. The purpose of this was to enable them know whether they have been doing passive teaching methods or participatory teaching methods. At the end of the exercise, it was obvious that the majority of the lecturers have been engaging in passive teaching. Thereafter, the facilitators used this as the starting point on how to teach the new techniques and methods to change 
teaching and learning perceptions and mind-sets that will be more participatory culminating in improved high-quality pedagogy. At this point in time, there was heated debate on whether the new technique will be beneficial to the law students bearing in mind that law is a unique course and has a traditionally entrenched way of being taught. The facilitator intervened and directed the attention of the participants to the new policy on teaching and learning in the higher education which is applicable to all courses taught at university level and law is inclusive. The facilitators also pointed out that various studies have shown that all disciplines can adapt to the new technique and that there is no problem in doing so provided the lecturers follow the laid down rules and procedures on assessments criteria. To allay the fears of the trainees, the facilitator indicated that by the end of the programme, the trainees will be able to apply and deliver pedagogy based on the new technique without hassles or stress. Pursuant to this, the trainees were asked to listen attentively during teaching in order to learn. They also impressed on the trainees that a lot of exercises, tasks and other assessment criteria will be used to deliver the teaching and learning. The importance of individual and group discussions were meticulously emphasised in view of the time constraint.

The facilitators emphasised on the preliminary stages that are required to conduct teaching and learning. The components of teaching model worksheet were used to explain how this works. One of the main components is the preplanning-planning phase consisting of the outcomes, assessment criteria, teaching and learning activities, learning tasks, assessments and methods. Lecturers were taught on how to go about this and different activities to test learning and understanding were done. At the end of the activities, it was apparent that the majority of the lecturers were, for the first time, knowing about pre-planning before teaching and learning. They found this very helpful and already well informed in what to teach unlike before when they just entered the class and started teaching, thereby confusing the learners. This technique was embraced by all with the belief that it will enhance the quality of teaching and learning.

During the course of teaching and learning, the lecturers are expected to consolidate on what have been taught so far. In order to know that learning has taken place, lecturers are supposed to ask questions and make them open-ended questions. At this stage, the lecturers are expected to allow the learners to reflect and think of possible answers to the questions. The lecturers are also expected to intervene by nominating learners at random to give answers. Any answer given, the lecturers should repeat them and use them to engage and interrogate further. This will allow for more participation by all the learners. The question-and-answers sessions will serve as an assessment tool that will enable the lecturer to know whether or not the learners have learnt from what have been taught.

The next component relates to the reflection of what was taught in order to identify areas for improvements. The lecturer should be satisfied that majority of the learners have learnt and are almost on the same page. If, however, it was revealed that responses to the questions were not up to standard or satisfactory, therefore, the facilitator needed to reflect on the teaching problems in learning in order for that to be addressed by changing the teaching technique.

The phrase constructive alignment was very strange to most of the lecturers because they had never heard of it nor been taught anything like that before. The facilitator unpacked the phrase and said that it was a combination of assessment instruments, assessment methods, assessments types, learning activities, teaching activities, assessment criteria and intended outcomes. By the time these were thoroughly explained to the trainees, they realised that they have been found wanting in aligning their teaching to this model. The explanation and teaching by the facilitator made them to be more understandable. At the end of the practical activities, trainees now appreciated better why it is important to align teaching and learning towards constructive alignment.

It was not surprising that when the facilitator introduced the Bloom's Cognitive Taxonomy Description and Verbs as a topic that the majority of the trainees were found wanting because they were unable to understand the meaning and application. The facilitator simplified it and broke it down to Recall (lower order) Remember (Knowledge); Understand (Comprehension), Application Level (Middle order) Apply and Analyse, Insight Level (Higher order) Evaluate and create. The purposes for these are to ensure that during teaching and learning, the learners are expected to recall what has been taught by remembering them and also understand them. Thereafter, they should be able to apply and analyse what they had learnt to real-life situation. And then be able to evaluate and create something out of what has been learnt. This will confirm that learning has occurred because of the new insight that will be generated. At the end of the training session and activities that followed, the majority of the trainers appreciated the importance of the Bloom's Taxonomy.

Training on the HEQSF level descriptors was considered as most significant because it was at this stage that all what have been taught would have to be practicalised. The HEQF is categorised from levels 5 to 10. Level 5 is the scope of knowledge in respect of which a learner is able to demonstrate an informed understanding; 6 is to demonstrate detailed knowledge and apply knowledge; 7 is to demonstrate, apply and evaluate; 8 is to demonstrate and engage in the field studied for purposes of understanding theories and research; 9 is to demonstrate specialist knowledge and be able to critique constructively; while 10 is to demonstrate expertise and critical knowledge with the ability to conceptualise new 
research initiatives and create new knowledge or practice.

Trainees also learnt about Assessment criteria and that no assessment should be marked without an already prepared memorandum or assessment instrument. To set the assessment, trainees were taught how to write learning outcomes and what it should contain thus: Verb + Noun + Condition (VNC) = Outcome. Most importantly, trainees were told to avoid to use know or understand in the learning outcomes because they are not fit and proper and therefore considered unreasonable.

The whole activities for a whole week was summarised and the very significant thing taught was on constructive alignment in teaching and learning. To achieve this, the facilitator insisted that there must be learning outcomes (Verb, Noun, Condition): under this, the lecturer must come up with what the students should achieve in clear terms. Followed by Assessment Criteria (Noun, Verb, Condition): under this, in order for the students to accomplish what the lecturer want them to achieve, the lecturer has to tell the students what to do, how to go about it in terms of what scholarly literature to read and all relevant scholarly works relevant to the subject matter. Then, teaching and learning activities will follow: At this stage, students are taught using the contemporary learning methods in line with the policy of the DoBE. At the same time, learning is expected to flow from the teaching. In order to establish that learning has taken place, there will be assessment tasks and methods: these can take various forms, ranging from individual or group oral class presentations, assignments, examinations and so on.

In the end, the training sessions were rounded up and each trainee was asked to explain what has been gained from the training and if learning had taken place or not. Trainees were also asked to mention if there were any challenges and problems. Summing up the overall responses of the trainees, it was generally agreed that the training had added academic and scholarly value to the trainees and will definitely improve the standard of pedagogy in the School of Law going forward. However, the trainees complained that the training was compressed and they were unable to grapple with other important aspects of the course because the facilitators merely glossed over them without digging deeper in explaining in order to improve understanding.

\section{Gaps Identified in Previous Methods of Pedagogy}

As earlier indicated, law lecturers have never received any formal training on how to teach in the higher education. Rather, they teach based on the qualifications received, which gave them the status of advocates and attorneys. But it must be pointed out that the only requirement relevant to teach law at the university is the possession of a Postgraduate Master's Degree and that will be adequate and sufficient to teach. It should also important to point out that law is a professional discipline, specifically meant for those who will become legal practitioners. At the same time, it is significant to be sensitive to the concern and fellers coming from the courts and employers of lawyers indicating poor performances and inability to provide good legal services to the clients. The society and scholarly research reports have indicated that poor academic performances on part of the students are due mainly to the problem of teaching and learning at the Universities by the lecturers. As part of transformation, the DoHE has therefore taken the lead and intervened by insisting that law pedagogy must also align with the current mode of teaching and learning in order to improve the quality and standard of teaching: transformative quality and effective value added. Law lecturers are now compelled, in addition to their law degrees, to go through formal training in teaching and learning in higher education.

\section{Challenges Encountered and Lessons Learnt from the Training}

Even though trainees generally agreed that the course presented them an opportunity to learn new method of teaching as prescribed by the DoHE, they still strongly felt that law, as a dynamic discipline, does not really need more of the regulatory and mandatory formal way of teaching. This is informed by virtue of the fact that law is regarded as a professional course and requires to be taught by incorporating professional methods, which calls for flexibility in teaching and learning. This point was heavily debated by the trainees and the facilitators. However, the facilitators reiterated that, even though law is a professional course, in so far as it is being taught at the university as a degree, it must align with the higher education and HEQSF, assessment and teaching.

What has really changed are the mode of assessment criteria and the learning outcomes. During the course of the training, it was discovered that majority of the lecturers haphazardly conducted assessments; something which was considered disadvantageous to the learners. The general opinion was, probably, that was one of the reasons for poor performances of the graduated and working lawyers at the workplaces. Most importantly, it was reiterated that research has proven that, with the new method of teaching and learning, standard and quality will be enhanced and improved; 
graduates will be able to fit in and function in any employment with minimum supervision. It was also extensively debated that since the old method had proven unsuccessful, the new method should be allowed to be the current method of teaching and learning. Movies of the old methods and the failure they produced were shown and, at the same time, movies of the new methods together with the scientific studies that confirmed their efficiencies and effectiveness were also show. Glaringly, trainees were able to watch and see the reality and impact of the two methods. To allay the fears of those who believed it will not work for law teaching and learning, the facilitators enjoined them to start applying what they have been taught and that gradually, with the passage of time, they will see that the benefits far outweigh the little or small concerns the were having.

\section{Conclusion}

The initiation of the training programme by the Director of the School, which was a sterling execution by the facilitators, was of immense value to the academic staff members in the School because lessons were taught, lessons were learn and teaching and learning occurred. This is expected to lead to enhance and produce high quality and standard pedagogy because it has upgraded standard and added value to the academic staff, and will improve overall scholarships in teaching and learning at all levels in the School. More importantly, previous conceived mind sets, perceptions and the business as usual attitudes of delivering pedagogy, to a greater extent have changed and the new methods of teaching and learning as prescribed, taught and learnt were considered by all the trainees to be very robust, contemporary and more engaging will culminate in producing well educated law graduates that will provide good performance and services to their clients whether they are corporates or individuals.

\section{Recommendations}

The one week training merely gave a generally overview of the new method of teaching and learning at the higher education. For there to be robust and perpetual value added, there is need for each academic staff to enrol and complete the full course which usually takes about six months to complete. Other law schools are also enjoined to subject their existing law lecturers to the training. Since it is now a requirement for teaching and learning, the belief that law is a discipline specific which makes teaching and learning unregulated and informal has started eroding. The best way out is to adapt to the new method. By so doing, the professionalism inherent in teaching and learning in law will improve and strengthen because of the quality of the newly introduced ways of conducting pedagogy to law students in the classrooms.

\section{References}

Ballantyne R, Bain JD, Packer J 1999. Researching university teaching in Australia: Themes and issues in academics' reflections, Studies in Higher Education, 24(2):237-257.

Barr RB and Tagg J 1995. From Teaching to Learning-A New Paradigm For Undergraduate Education. Change: The Magazine of Higher Learning, 27(6): 12-26.

Biggs J 2001. The reflective Institutions: Assuring and Enhancing the quality of Teaching, Higher Education, 41:221-238.

Biggs J, Tang C 2011. Teaching for quality learning at university, Open University Press, Berkshire, UK.

Biggs J, Tang C 2011. Teaching for quality learning at university, Open University Press, Berkshire, UK.

Coaldrake P, Stedman L 1999. Academic Work in the Twenty-first Century Changing roles and policies, 99H Occasional Paper Series,igher Education Division Department of Education, Training and Youth Affairs.

D'Amato A 1987. Decline and Fall of Law Teaching in the Age of Student Consumerism, Journal of Legal Education, 37:461-472.

Daniel J 2010. Mega-Schools, technology and teachers: Achieving education for all, Routledge Publishers, Oxon, UK.

Darling-Hammond L, 1999. Teacher quality and student achievement: A review of state policy evidence, Centre for the Study of Teaching and Policy, A National Research Consortiu, University of Washington, USA.

Fullan M 2007. The new meaning of educational change, Teachers College Press, New York, USA.

Garrison DR, Kanuka H 2004. Blended learning: Uncovering its transformative potential in higher education, The Internet and Higher Education, 7(2):95-105.

Healey M 2000. Developing the Scholarship of Teaching in Higher Education: A discipline-based approach. Higher Education Research \& Development, 19(2): 169-189.

HEDSC, 2013. Higher Education Development and Support Curriculum Development and Support, The art of Teaching in Higher Education, Tshwane University of Technology, Pretoria South Africa, p. 2.

Livingstone DW 2004. The education-jobs gap: Underemployment or economic democracy, Garamond Press Ltd, Ontario, Canada.

Lueddeke GR 2003. Professionalising Teaching Practice in Higher Education: A study of disciplinary variation and 'teaching-scholarship, 
Studies in Higher Education, 28(2): 213-228.

Moyles J, Georgeson J, Payler J 2011. Beginning teaching, beginning learning Open University Press, Berkshire, UK. Renton J 2009. Coaching and Mentoring: What They are and how to Make the Most of Them, Bloomberg Press, USA.

Rosenthal L 2011. Those Who Can't, Teach: What the Legal Career of John Yoo Tells Us about Who Should Be Teaching Law, Mississippi Law Journal 80(4):1563-1631.

Sterling S 2012. Sustainability Education: Perspectives and Practice across Higher Education, Earthscan Publishers, New York, USA. Thomas L, Hafemeister JD, James R P, Ogloff JD, Mark A, Small JD 1990. Training and careers in law and psychology: The perspective of students and graduates of dual degree programs. Behavioral Sciences \& the Law, 8(3): 263-283.

Trail T, William R, Underwood W D 1996. Decline of Professional Legal Training and a Proposal for Its Revitalization in Professional Law Schools, Baylor Law Review, 48:201-211.

Von Glasersfeld E 1989. Cognition, construction of knowledge, and teaching, 80(1):121-140. 
